\title{
Experimental Pseudomonas aeruginosa mediated rhino sinusitis in mink
}

\author{
Kirkeby, S.; Hammer , A. S.; Høiby, N.; Salomonsen, Charlotte Mark
}

Published in:

International Journal of Pediatric Otorhinolaryngology

Link to article, DOI:

10.1016/j.ijporl.2016.12.037

Publication date:

2017

Document Version

Peer reviewed version

Link back to DTU Orbit

Citation (APA):

Kirkeby, S., Hammer , A. S., Høiby, N., \& Salomonsen, C. M. (2017). Experimental Pseudomonas aeruginosa mediated rhino sinusitis in mink. International Journal of Pediatric Otorhinolaryngology, 96, 156-163.

https://doi.org/10.1016/j.ijporl.2016.12.037

\section{General rights}

Copyright and moral rights for the publications made accessible in the public portal are retained by the authors and/or other copyright owners and it is a condition of accessing publications that users recognise and abide by the legal requirements associated with these rights.

- Users may download and print one copy of any publication from the public portal for the purpose of private study or research.

- You may not further distribute the material or use it for any profit-making activity or commercial gain

- You may freely distribute the URL identifying the publication in the public portal

If you believe that this document breaches copyright please contact us providing details, and we will remove access to the work immediately and investigate your claim. 


\section{Accepted Manuscript}

Experimental Pseudomonas aeruginosa mediated rhino sinusitis in mink

S. Kirkeby, A.S. Hammer, N. Høiby, C.M. Salomonsen

PII: S0165-5876(16)30474-8

DOI: $\quad$ 10.1016/j.ijporl.2016.12.037

Reference: $\quad$ PEDOT 8372

To appear in: International Journal of Pediatric Otorhinolaryngology

Received Date: 8 July 2016

Revised Date: 25 December 2016

Accepted Date: 26 December 2016

Please cite this article as: S. Kirkeby, A.S. Hammer, N. Høiby, C.M. Salomonsen, Experimental Pseudomonas aeruginosa mediated rhino sinusitis in mink, International Journal of Pediatric Otorhinolaryngology (2017), doi: 10.1016/j.jporl.2016.12.037.

This is a PDF file of an unedited manuscript that has been accepted for publication. As a service to our customers we are providing this early version of the manuscript. The manuscript will undergo copyediting, typesetting, and review of the resulting proof before it is published in its final form. Please note that during the production process errors may be discovered which could affect the content, and all legal disclaimers that apply to the journal pertain. 
S. Kirkeby

Correspondance: S. Kirkeby, Department of Oral Medicine, Dental School, Panum Institute, University of Copenhagen, Nørre Alle 20, 2200 Copenhagen N, Denmark. e-mail: skir@sund.ku.dk

A.S Vedsted Hammer: Department of Vetenary Disease Biology, University of Copenhagen,

N. Høiby: Department of Clinical Microbiology, Rigshospitalet , \& Institute for Immunology and Microbiology, University of Copenhagen,Copenhagen, Denmark.

C. M. Salomonsen: National Veterinary Institute, Technical University of Denmark, Aarhus, Denmark 


\section{Abstract.}

Objectives: The nasal and sinus cavities in children may serve as reservoirs for microorganisms that cause recurrent and chronic lung infections. This study evaluates whether the mink can be used as an animal model for studying Pseudomonas aeruginosa mediated rhino-sinusitis since there is no

6 suitable traditional animal model for this disease.

Methods: Nasal tissue samples from infected and control mink were fixed in formalin,

8 demineralized, and embedded in paraffin. A histological examination of sections from the infected animals revealed disintegration of the respiratory epithelium lining the nasal turbinates and swelling and edema of the submucosa. The expression of mucins and sialylated glycans was examined using immunohistochemistry.

Results: MUC1, MUC2 and MUC5AC were upregulated in the inoculated animals as a much stronger staining was present in the respiratory epithelium in the infected animals compared to the controls and MUC5B appeared in large macrophage-like cells in the submucosa. The goblet cells in the nasal epithelium from the infected mink showed high affinity to the Maackia amurensis lectin and anti-asialo GM1 indicating a high concentration of $\alpha 2-3$ sialic acid respectively $\beta$ GalNAc1$4 \mathrm{Gal} \beta$ containing glycans in these mucin producing cells. The nasal cavity in the infected mink thus shows features of carbohydrate expression comparable to what has been described in the respiratory system after Pseudomonas aeruginosa infection in humans. mediated rhino-sinusitis.

Key words: rhino-sinusitis, Pseudomonas aeruginosa, mink, mucin, sialic acid 


\section{Introduction.}

We here evaluate the mink as a suitable animal model for experimental $P$. aeruginosa produced rhino sinusitis based on micromorphology and by use of antibodies and lectins directed against glycoconjugates.

Pseudomonas aeruginosa exists in nature in many forms and colonizes a number of different mucosal surfaces such as the respiratory, ocular, digestive, and reproductive mucosa. Epithelial cells from several tissues show a differential sensitivity to P.aeruginosa adherence [1].

The membranes of the airways in both man and mink are covered with a viscous colloid layer named mucus. The major components in mucus are mucins which are highly glycosylated proteins. $P$ aeruginosa adhesins/lectins may play an important role for the colonization in immuno deprived patients since the bacterium adheres to mucins and other epithelial glycoconjugates [2-4]. The bacterium also causes colonization in most patients with cystic fibrosis (CF).

$\mathrm{CF}$ is caused by mutations in the transmembrane conductance regulator (CFTR) gene leading to decreased volume of airway epithelial lining fluid and letting go of mucus and thereby facilitating recurrent and chronic lung infections notably with $P$. aeruginosa growing as alginate containing biofilm [5-7]. Until now none of the transgenic cystic fibrosis mouse models that have been developed mimics the feature of human $\mathrm{CF}$ disease with chronic lung infection by mucoid strains of P. aeruginosa. [8-10]. The rabbit is often used as an animal model of sinusitis $[11,12]$. In this study we evaluate the mink as an alternative to study the pathogenesis of $p$. aeruginosa mediated sinusitis for several reasons. 1) The mucosal histology of both the upper and lower respiratory tracts in humans and mink are much alike. 2) $P$. aeruginosa is normally an organism of low invasiveness and low virulence in experimental laboratory animals and studies in the pathogenesis of its pathogenesis are hindered because of the inherent resistance of most species to disease of this 
1 organism . However, it seems that the mink is the only animal species to develop fatal and 5 goblet cells in the mink airways [18].

6 Chronic rhino sinusitis with inflamed tissue and mucosal edema leads to decreased ciliary function

7 and enhanced bacterial colonization. Consequently viscous mucus is present in most CF patients

8 and the paranasal sinuses constitute an alternative colonization site [19]. The contaminating contagious hemorrhagic pneumonia caused by P. aeruginosa [13-15]. 3) Mink are also susceptible to pulmonary infection with an experimental intra-tracheal or intra-nasal inoculation $[16,17]$. 4) We have previously shown that the lectins from $P$. aeruginosa bind to the submucosal glands and

bacterium in the upper airways is predominantly $P$. aeruginosa as in the lungs [20].

Mucus forms a surface layer on the airways and serves as a first line of defense during airway infection. At least 16 mucin genes have been cloned in the lung and data suggest that some of them play a defensive role during pseudomonas infection [4,21].

Mucins are high-molecular weight, multifunctional glycoproteins that contain an elevated percentage of serine, threonine and proline in addition to a large quantity of complex O-linked oligosaccharides. The mucins are often classified as being membrane bound, or they are secreted non-gel-forming or secreted gel-forming mucins. In the airways they are produced by goblet cells in the surface epithelium and from submucosal glands. Mucins play a regulatory role in normal epithelial tissues. In the airways they protect and lubricate the respiratory tract [22]. They bind bacterial and viral pathogens as their anti-inflammatory role may be mediated through inhibition of toll-like receptor signaling [23]. In the present study we have explored the in situ binding to the nasal sections using antibodies directed against a number of mucins. Relevance for the mucins used for the study of infection (nomenclature for mucins: MUC in human; muc in mouse and Muc in other animal models (rat and chinchilla). 
1 MUC1: The mucin is a membrane-tethered mucin that interacts with $P$. aeruginosa through

2

4 flagellin [24].

MUC2: Is highly elevated at the mRNA level in cystic fibrosis airways and following exposition $P$. aeruginosa [25].

MUC3: Seems not to be involved in pseudomonas infection. Expression of the mucin is therefore used as a negative control.

MUC4: The mucin was downregulated in mice infected with Pseudomonas aeruginosa [26]

MUC5AC: Is highly elevated at the mRNA level in cystic fibrosis airways and following exposition to P. aeruginosa [25]

MUC5B: The mucin is present in cystic fibrosis airway secretions [27].

MUC16: Is a membrane anchored mucin that that provides a barrier to bacterial adherence and invasion of epithelial cells [28].

When produced in excess, the mucus may contribute to the morbidity and mortality associated with respiratory diseases. Many mucins are highly sialylated and alteration of the sialic acid content are frequently associated with viscosity in mucins and impaired mucociliary transport leading to bacterial infection and inflammatory cell infiltration in the respiratory tract as in rhinosinusitis and bronchitis [29].

To study the impact of sialic acid epitopes in the normal and P.aeruginos inflamed tissue we used the following lectins and antibodies: Maackia amurensis lectin (MAA) which is specific for Sialyla2-3Gal [30], Sambucus nigra lectin (SNA) which is specific for the Sialyla2-6Gal linkage [31] . Anti-ganglioside GM1 that detects Gal $\beta 1-3$ GalNAc $\beta 1-4[$ Sialyl $\alpha 2-3]$ Gal $\beta 1-4 G l c \beta 1$-ceramide and Anti-asialo-ganglioside GM1 that detects Gal $\beta 1-3 \mathrm{GalNAc} \beta 1-4 \mathrm{Gal} \beta 1-4 \mathrm{Glc} \beta 1$-ceramide. 
1 The results will provide information on the use of mink as an experimental model for $P$. aeruginosa

2 infection with inflammation and increased mucin production in the sinus-nasal cavity.

3

4

5

6

7

9

10

11

12

13

14

15

16

17

18 


\section{$1 \quad$ Materials and methods.}

2 The mink were assigned to individual cages and with separate water supply. All animal experiments

3 were conducted at the National Veterinary Institute, Technical University of Denmark in

4 accordance with both institutional and national guidelines (Danish Animal Experiments

5 Inspectorate, Permit Number: 2012-15-2934-00524). The experiments were approved by the Danish

6 Animal Care and Ethics Committee, Denmark. The $P$. aeruginosa isolate used for infection was

7 recovered from an outbreak of hemorrhagic pneumonia in mink on the Danish island Mors in 2008

8 (Difco serotype O6, laboratory journal number at the National Veterinary Institute: 2008-52-937).

9 This isolate was used because the O-antigen of B-band bacterial lipopolysaccharide contributes to initial damage and inflammatory responses in human lungs.

11 Four mink were infected intra-nasally with $0.5 \mathrm{ml} P$. aeruginosa with $3.7 \times 10^{3}-10^{7}$ colony forming units $(\mathrm{cfu}) / \mathrm{ml} 0.9 \%$ saline. The concentration of the bacterial solution was determined using the plate count method. Another four mink served as controls and received $0.9 \%$ saline intranasally.

Four days after infection the minks were euthanized. Swabs were taken from the nasal cavity and from the lung. For a more detailed procedure see Salomonsen et al. $(13,14)$ The swabs were stroked on blood agar and grown at $37^{\circ} \mathrm{C}$ for 24 hours. The $P$. aeruginosa cultured from the nasal cavities had pulsed-field gel electrophoresis (PFGE) types indistinguishable from the isolate used for intranasal infection.

The mink were anesthetized with a ketamine/xylazin mixture injected intramuscularly and euthanized with an injection of T-61 (MDS-Animal Health, Boxmee, the Netherlands) in the liver. The nasal tissue samples were dissected immediately after the animals were euthanized. 
1 The nasal tissue samples were prepared by cutting the nose in the dorsal plane right above the hard

2 palate and transversally at the level of the eyes so that a large piece of the nasal cavity could be

3 separated from the head. This nasal block was then fixed in 10\% formalin for 1-2 days and

4 demineralized in 14\% EDTA with $1.5 \% \mathrm{w} / \mathrm{v} \mathrm{NaOH}$ for 3 days, and embedded in paraffin.

$5 \quad$ The paraffin blocks were cut in $3 \mu \mathrm{m}$ sections and used for histochemical procedures

$6 \quad$ Histochemistry

7 The following antibodies were used in this study:

8 Anti-MUC1 from Abcam (ab.1548) is a rabbit polyclonal antibody. The immunogen was a

9 synthetic peptide with amino acid sequence from the cytoplasmic tail. Sections from human

10 submandibular gland served as positive controls. Anti-MUC2 from Abcam (ab. 134119) is a rabbit

11 monoclonal antibody. The immunogen was a synthetic peptide corresponding to a region with human MUC2. Sections from human colon served as positive controls.

13 Anti-MUC3 from biobyt (orb95411) is a rabbit polyclonal antibody. According to the manufactures 14 is reacts in tissues from human, mouse and rat). Anti-MUC4 from Santa Cruz (sc33654) is a mouse monoclonal $\mathrm{IgG}$ antibody raised against the transmembrane domain of rat mucin4. Anti-MUC5AC from MyBioSource (MBS2525387) is a rabbit polyclonal antibody. The immunogen was a

17 synthetic peptide of human MUC5AC. Anti-MUC5B is a mouse monoclonal antibody from Abcam 18 (ab77995). The immunogen was an un-glycosylated serine and threonine free, synthetic peptide from the N-terminal region of human MUC5B. Anti-MUC16 from Abcam (ab133419) is a rabbit polyclonal antibody. The immunogen was a synthetic peptide from internal sequence amino acids of

21 human MUC16. Sections from human lung served as controls. 
1 The following lectins and antibodies were used to demonstrate sialic acid residues. Biotinylated lectins from Maackia amurensis (MAA) and Sambucus nigra (SNA) (EY Laboratories; San Mateo,

3 CA, USA). Sections from ferret lung tissue served as positive controls [32]. To study the binding of

4 sialylated and non-sialylated glycosphingolipids we used antibodies against ganglioside GM1 and 5 asialo-ganglioside GM1 [33]. Anti-GM1 from Calbiochem is rabbit polyclonal antibody and Anti6 asiolo-GM1 is a rabbit polyclonal antibody from LifeSpan.

7 Presence of phagocytic cells in the sections was demonstrated using an anti-myeloperoxidase 8 antibody (Antibodies online Cat No: ABIN 1689910) that detects antimicrobial activity in inflamed 9 tissue [34]. Presence of bacteria in the sections of the nasal tissue was detected with anti- 


\section{Results.}

As in in the human organ, the mink nasal cavities are lined by a pseudostratified ciliated epithelium with goblet cells (Figs.1A and C). The lamina propria below the respiratory epithelium is richly vascular. The spaces between the turbinates (air channels) are normally empty but sparse cellular debris may be present. Both the human and mink submucosa contain exocrine glands but there fewer submucosal glands in the mink submucosa than in the human equivalent. An exception is the submucosa below the olfactory epithelium which contains numerous exocrine glands (Fig.1E).

The pseudostratified mucosal nasal epithelium was disintegrated and the loose connective tissue beneath the respiratory epithelium showed swelling and edema in the infected animals. A cellular accumulation was observed in the loose connective tissue in the turbinates and in the air channels from the P. aeruginosa inoculated mink (Figs.1B and D). The Alcian blue/PAS staining revealed that many cells in the debris between the turbinates were Alcian blue positive (Fig.1D). The connective tissue and the glands in the olfactory area of the nasal cavity was seemingly unaffected by the infection (Fig.1F) in contrast to what was observed in the respiratory part of the nasal cavity.

To decide if phagocytes had infiltrated the inflamed tissue some sections were incubated to show presence of myeloperoxidase containing cells. The turbinates in healthy mink displayed no sign of inflammation while the turbinate submucosa from the infected mink was loaded with myeloperoxidase positive cells (Figs.2A and B). Immuno-staining with an antibody against Pseudomonas aeruginosa served to verify bacterial accumulation in the inoculated animals. There was no immuno- reaction in sections from the control animals, while the air channels in the nasal cavities from the infected mink were loaded with strongly reacting debris (Figs.2C and D).

The expression of both MUC1 and MUC2 in the inoculated animals seems to be upregulated since there was a much stronger anti-MUC1 and anti-MUC2 staining in the respiratory epithelium from 
1 the infected animals compared to the controls (Figs.3A-D). A sparse fine-granular anti-MUC1 reaction was present in the respiratory epithelium in the control mink while both the glycocalyx and the cell surfaces reacted strongly in the infected animals. MUC2 staining in the mucosal glycocalyx was noticed in both control and diseased animals. However, a strong i MUC2 reaction in the goblet cells was present only in the infected mink. Incubation with anti-MUC16 resulted in a weak and scattered staining in the surface epithelial cells from both groups of mink. . Incubation with anti MUC3 and anti-MUC4 showed no staining. A few goblet cells were stained in the control mink by anti-MUC5AC while numerous MUC5AC positive cells were observed in the infected animals (Fig 3E and F).

While the surface epithelium from both the healthy and infected mink displayed an intense finegranular MUC5B reaction it was only the submucosa from the $P$ aeruginosa infected mink that contained large MUC5B positive cells (Figs 4A and B). Potential changes in expression of sialic acid in pseudomonas infection were investigated by incubation with anti-GM1, anti-asialo-GM1, and the lectins MAA and SNA. Most of the respiratory epithelial cells showed a moderate staining intensity with anti-GM1 in both control and diseased animals. Incubation with asialo-GM1 resulted in strongly reacting with the nasal epithelial cells from the infected mink while the antibody did not stain the cells from the control mink (Figs.4C and D). The mucosal glycocalyx in both groups of animals reacted with the sialic acid detecting lectin MAA. However, the lectin staining revealed few MAA positive goblet cells in the sections from the healthy animals while there was numerous stained goblet cells in the sections from the inoculated animals (Fig E and F). Incubation with SNA resulted in staining of occasional goblet cells in both groups of animals. 


\section{Discussion.}

The purpose of the study was to describe the pathological consequences of an experimental P.aeruginosa rhinosinuitis in mink and thereby to evaluate the mink as an animal model for $P$. aeruginosa mediated infection. The same mink that were used in the present study have previously been examined for pathological changes in their lungs associated with Pseudomonas aeruginosa and it was concluded that the infected animals had developed typical hemorrhagic pneumonia [13, 14].

To serve as a model for airway infections the mucosal histology in the respiratory tract from mink and humans should be much alike. In both species the nasal cavity, the paranasal sinuses and the tracheobronchial tree are lined by a pseudostratified columnar, ciliated epithelium with numerous goblet cells. The respiratory epithelium is supported by a richly vascular connective tissue containing exocrine glands.

The micromorphology of the mink and human airway systems is thus in many ways comparable. Lung and sino-nasal infections in humans with $P$. aeruginosa causes inflammation of the mucosal tissue $[20,35,36]$ and we here show that the $P$. aeruginosa infected mink also expresses typical signs of inflammation and edema in the submucosa and disintegration of the nasal mucosa.

\section{Inflammation markers.}

Cells stained by the antibody directed against myeloperoxidase invaded the submucosa from the infected mink indicating the presence of neutrophils in the loose connective tissue [34]. Further, the air channels were stuffed with debris reacting with the antibody against $P$. aeruginosa. The $P$ aeruginosa cultured from the nasal cavities had pulsed-field electrophoresis types indistinguishable from the isolate used for intranasal infection. We therefore conclude that the inoculation of the minks was successfully performed. 


\section{Mucins.}

Changes of the carbohydrate sequences of respiratory could alter the mucus properties leading to ineffective mucociliary clearance and to bacterial colonization and infection [37]. The respiratory tract holds several mucin types. We have focused on the expression of some mucins that all have been detected in the human airways.

\section{MUC1}

MUC1 is a transmembrane mucin which is expressed on the apical surface of many epithelial cells as well as hematopoietic cells. The mucin is primarily involved in the protection of epithelial surfaces and contributes to the mucosal barrier to infection. MUC1 seems to play an important role in P. aeruginosa infections since the mucin suppresses inflammatory responses induced by the bacterium. Measurements of lung tissue lysates have shown that MUC1 levels in wild type mice is initially low, but gradually increases after P. aeruginosa inhalation [38] and the mucin may prevent lung injury in mice models of repetitive P. aeruginosa infection [39].

The mucin contributes to the mucosal barrier to infection and the mucin suppresses inflammatory responses induced by $P$. aeruginosa. Lillehoj et al. $[40,41]$ have showed that MUC1 mucins on the epithelial cell surface are adhesion sites for $P$. aeruginosa flagellin. We observed that only a weak granular reaction was present in the respiratory epithelium in the control mink after incubation with anti-MUC1 while both the glycocalyx on the cell surface and the cell membranes in the respiratory epithelial cells reacted strongly in the infected animals.

\section{MUC2}

The surface epithelium in the intestine is coated with a thick protective MUC2 mucin while this gelforming mucin is absent or very scarcely present in the mucous gel of normal airways [42] $P$. 
aeruginosa infection leads to upregulation of the mucin gene MUC2 in both humans and animals $[43,44]$. The upregulation of MUC2 during airway inflammation induced by bacterial infection could be important to protect the tissue from inflammatory cells

We here show that the nasal surface epithelium in both the healthy and the infected mink was coated with a glycocalyx that stained strongly after incubation with anti-MUC2. A cytoplasmic reaction was however only noticed in the epithelial cells infected with $P$. aeruginosa. Mucin2 is a glycoprotein that is secreted predominantly from the goblet cells and it seems that intracellular staining of anti-MUC2 in the epithelial cells suggests that $P$. aeruginosa can stimulate secretion of this mucin in the airways.

MUC3, MUC5AC, MUC5B, MUC16.

MUC3 is a transmembrane glycoprotein that is expressed in normal colon and in very low levels in the respiratory tissues [45]. In contrast to the strong activity we noticed with the transmembrane mucin MUC1 our results show no immmunostaining with anti-MUC3 in $P$. aeruginosa infected mink. Both mucin 2 and mucin 5AC are produced in goblet cells. We noted an increased immuno staining in the goblet cells with anti-MUC2 and anti-MUC5AC after $P$. aeruginosa infection but the glycocalyx reacted only with anti-MUC2. Chorley et al [46] likewise noticed a differential MUC2 and MUC5AC secretion by tracheal cells. MUC5B is required for airway defense and Sepper et al (47] found that expression of the mucin in lung alveolar macrophages was increased in long-term smokers and in mice infected by multiple bacteria there was an increased secretion of Muc5B and macrophage activity in the airways [48]. We demonstrated large Muc5B positive macrophage-like cells in the nasal submucosa. Also MUC16 are attributed to airway goblet cells [40]. Muc16 is a cell surface mucin that provides a barrier to bacterial adherence but only a few MUC16 positive cells were observed in the two animal groups. 
1 Increased production of airway mucins seems to be prerequisite in establishing a bacterial biofilm in

2 the airways. The virulence of P. aeruginosa is partly dependent by its ability to form a biofilm and

3 this bacterial biofilm contributes to the pathogenesis of chronic rhino-sinusitis. We show increased

4 staining of antibodies directed against mucin1, mucin2 and mucin5AC and mucin $5 \mathrm{~B}$ in the nasal

5 turbinates from mink infected with P. aeruginosa.

\section{$6 \quad$ Sialic acids.}

7 Sialic acids are nine-carbon sugar residues present on glycosphingolipids, N-glycans and O-

8 glycans. $\mathrm{N}$-Acetylneuraminic acid (NeuAc) is the exclusive sialic acid in humans and thus often

9 referred to simply as sialic acid. The sugar occupies the terminal position within glycan molecules

10 on the surface of vertebrate cells and serves as receptors for many pathogenic bacteria and viruses.

11 Inflammation may modify the appearance of glycoproteins [41] and carbohydrates containing sialic

12 acid change level of expression in the respiratory tract during infection . Gallego and Hulen [1]

13 have shown that variable amount of sialic acid in the epithelial cell surface glycoconjugates causes

14 differential sensitivity to P. aeruginosa adherence.

15 It has long been established that mucins and sialic acid act as receptors for $P$ aeruginosa in the respiratory tract $[49,50]$. Mucins are rich in sialic residues and sialylation may be altered in the

17 mucin in CF patients suffering from $P$. aeruginosa infection. In the present study we have used 18 lectins and glycosphingolipids as markers to detect presence sialic acid epitopes in the mink nasal tissue. Some studies have shown a shift from a $\alpha 2-6$ sialic acid linkage to a $\alpha 2-3$ sialic acid linkage [51]. MAA is a lectin that binds with high affinity to oligosaccharides containing terminal sialic acid linked 2-3 to penultimate galactose residues. We here show that in the infected nasal epithelium it is the goblet cells that are upregulated with $\alpha 2-3$ sialic acid containing glycans. 
1 Incubation with SNA implies that there was no upregulation of $\alpha 2-6$ sialic acids in mink nasal

2 tissues.

3 Sialic acid is not the only carbohydrate-receptor that is vital for binding $P$. aeruginosa. The

4 glycosphingolipid GM1 contains one sialic acid residue bound to galactose. Incubation with this

5 ganglioside showed no differences in the sparse immuno-staining between sections from infected

6 and non-infected animals. When the sialic acid residue is removed from the ganglioside GM1 as in

7 asialo-ganglioside GM1 then antibody staining showed no reaction in the nasal tissue from the

8 control mink while there was a strong asialo-GM1 expression in the infected tissue. This result is in

9 concordance with Bentzmann et al [52]) who observed that the pili of $P$ aeruginosa bind

10 specifically to the carbohydrate sequence $\beta$ GalNAc1-4Gal $\beta$, a disaccharide sequence present in

11 asialo-GM1.

12 A marked association exists between upper and lower airway cultures in patients with CF since the 13 paranasal sinuses often are colonized with matching CF lung bacteria [53] and treatment of the 14 infection in both the lung and paranasal sinuses is thus important [54].

Conclusions.

17 Since the nasal cavity from mink with acute $P$. aeruginosa infection displays carbohydrate expression comparable to what is described as a chronic biofilm-based infection in the respiratory system we suggest that the mink can be used to study $P$. aeruginosa mediated rhino-sinusitis. The genome of the mink seems not yet to have been sequenced which is a serious drawback when it comes to design molecular reagents for the use of experiments with this animal. 
1 ASH, NH, CMS conceived and designed the experiments. CMS performed the experiments. SK

The authors declare that they have no conflict of interest.

\section{References.}

[1] Gallego MP, Hulen C (2006) Influence of sialic and bacterial sialidases on differential adhesion of Pseudomonas aeruginosa to epithelial cells. Colloids and Surfaces B 52: 154-156.

[2] Perret S, Sabin C, Dumon C, Pokorna M, Gautier C, Galanina I S, Bovin N, Nicaise M, Desmadriil M, Gilboa-Garber N, Wimmerova M, Mitchell EP, Imberty A (2005) Structural basis for the interaction between human milk oligosaccharides and the bacterial lectin PA-IIl of Pseudimonas aeruginosa. Biochem J 389: 325-332.

[3] Kirkeby S, Hansen A K, d Àpice A, Moe D (2006) The galactophilic lectin (PA-IL, gene LecA) from Pseudomonas aeruginosa. It binding requirements and localization of lectin receptors in various mouse tissues. Microb. Pathog 40: 191-197.

[4] Kim CK (2012) Role of epithelial mucins during airway infection. Pulm Pharm Ther 25: 415-419.

[5] Boucher RC (2004) New concepts of the pathogenesis of cystic fibrosis lung disease. Eur Resp J 23: 146-158.

[6] Bjarnsholt T, Østrup Jensen PØ, Fiandaca MJ, Pedersen J, Hansen CR, Andersen CB, Pressler T, Givskov M, Høiby N (2009) Pseudomonas aeruginosa in the respiratory tract of cystic fibrosis patients. Pediatr Pulmonol 44: 547-558. 
[7] Stoltz DA, Meyerholtz DK, Welsh MJ (2015) Origins of cystic fibrosis lung disease. NEJM 372: 351-362.

[8] Coleman FT, Mueschenborn S, Meluleni G, Ray C, Carey VJ, Vargas SO, Cannon CL, Ausubel FM, Pier GB (2003) Hypersusceptibility of cystic fibrosis mice to chronic pseudomonas aeruginosa oropharyngeal colonization and lung infection. Proc. Natl Acad Sci USA 100: 1949-1954.

[9] Kukavica I and Levesque RC (2008) Animal models of chronic lung infection with Pseudomonas aeruginosa: useful tool for cystic fibrosis studies. Lab Anim 42: 389-412.

[10] Facchini,M, De Fino, I, Riva C, Bragonzi V (2014) Long term chronic Pseudomonas aeruginosa infection in mice. J Vis Exp e51019 doi 10.3791/51019.

[11] Kara CO. (2004) Animal models of sinusitis: relevance to human disease. Curr Allergy Astma Rep: 4: 496-499.

[12] Palmer J (2006) Bacterial biofilms in chronic rhinosinusitis. Ann Otol Rhinol Laryngol Suppl 196: 35-39.

[13] Hammer AS, Pedersen K, Andersen TH, Jørgensen JC, Dietz HH (2003) Comparison of Pseudomonas aeruginosa isolates from mink by serotyping and pulsed-field gel electrophoresis. Vet Microbiol 94: 237-243.

[124 Salomonsen CM, Boye M, Høiby N, Jensen TH, Hammer AS (2013a) Comparison of histological lesions in acute hemorrhagic pneumonia in mink associated with Pseudomonas aeruginosa or Escherichia coli.Can J Vet Res 77: 199-204. 
[15] Salomonsen CM, Chriél M, Jensen TH, Rangstrup-Christensen L, Høiby N, Hammer AS (2013b) Effect of infectious dose and season on development hemorrhagic pneumonia in mink caused by Pseudomonas aeruginosa. Can J Vet Res 77: 221-225.

[16] Long GG, Gallina AM, Gorham JR (1980) Pseudomonas pneumonia of mink: pathogenesis, vaccination and serologic studies. Am J Vet. Res 41: 1720-1725.

[17] Shimizu, T, Homma JY, Abe C, Tanamoto T, Aoyama Y, Okada K, Yanagawa R, Fujimoto, Y, Noda H, Takashima I 81976) Effect of common protective antigen vaccination to protect mink from challenge exposure with Pseudomonas aeruginosa. Am J Vet Res 37: 14411444.

[18] Kirkeby S, Wimmerova M, Moe D, Hansen AK (2007) The mink as an animal model for Pseudomonas aeruginosa adhesion: binding of the bacterial lectins (PA-IL and PA-IIL) to neoglycoproteins and to sections of pancreas and lung tissues from healthy mink. Microb. Infect 9: 566-573.

[19] Hansen SK, Rau MH, Johansen HK, Ciofu O, Jelsbak L, Yang L, Folkesson A, Jarmer HØ, Aanæs K, von Buchwald C, Høiby N, Molin S (2012) Evolution and diversification of Pseudomonas aeruginosa in the paranasal sinuses of cystic fibrosis children have implications for chronic lung infection. The ISME Journal 6: 31-45.

[20] Aanæs K (2013) Bacterial sinusitis can be a focus for initial lung colonisation and chronic lung infection in patients with cystic fibrosis. J Cyst Fibros 12: S1-S20.

[21] Haley CL, Colmar-Hamood JA, Hamood AN (2012) Characterization of biofilm-like structures formed by Pseudomonas aeruginosa in a synthetic mucus medium. BMC Microbiology 12:181. 
[22] Ishibashi Y, Imai S, Inouye Y, Okano T, Taniguchi A (2006) Effects of carbocisteine on sialyl-Lewis $\mathrm{x}$ expression in an airway carcinoma cell line stimulated with tumor necrosis factor- $\alpha$. Eur J Pharmacol 530: 223-228.

[23] Bernstein JM, Reddy M (2000) Bacteria-mucin interaction in the upper aerodigestive tract shows striking heterogeneity: implications in otitis media, rhinosinusitis and pneumonia. Otolaryngol Head Neck Surg 122: 514-520.

[24] Lu W, Hisatsune A, Koga T, Kato, K, Kuwahara I, Lillehoj EP, Chen W, Cross AS, Gendler SJ, Gewirtz AT, Kim KC (2006) Cuttig Edge: enhanced pulmonary clearance of Pseudomonas aeruginosa by Muc1 knockout mice. J Immunol 176: 3890-3894.

[25] Mohamed FB, Garcia-Verdugo I, Medina M, Balloy V, Chignard M, Ramphal R, Touqui L (2012) A crusial role of flagellin in the induction of airway mucus production by Pseudomonas aeruginosa. PLoS ONE 7(7): e39888, doi:10.1371.

[26] Tetaert D, Pierre M, Demeyer D, Husson MO, Beghin L, Galabert C, Gottrand F, Beermann C, Guery B, Desseyn JL (2007) Dietary n-3 fatty acids have suppressive effects on mucin upregulation in mice infected with Pseudomonas aeruginosa. Resp Res. 8:39 doi:10:1 $186 / 1465-9921-8-39$.

[27] Davies JR, Svitacheva N, Lannefors L, Kornfalt R, Carlstedt I (1999) Identification of MUC5B, MUC5AC and small amounts of MUC2 mucins in cystic fibrosis airway secretions. Biochem J 344: 321-330.

[28] Gipson IK, Spurr-Michaud S, Tisdale A, Menon BB (2014) Comparison of the transmembrane mucins MUC1 and MUC16 in epithelial barrier function. PLoS ONE 9(6): e:100393. doi:10.1371. 
[29] Menon BB, Kaiser-Marko C, Sporr-Michaud S, Tisdale AS, Gipson IK (2015)

Suppression of Toll-like receptor-mediated innate immune responses at the ocular surface by the membrane-associated mucins MUC1 and MUC16. Immunology 8: 1000-1008.

[30] Wang WC, Cummings RD (1988) The immobilized leukoagglutinin from the seeds of Maackia amurensis binds with high affinity to the complex-type Asn-linked oligosaccharides containing terminal sialic-acid-linked alpha-2,3 to penultimate galactose residues. J Biol Chem 263. $4576-4585$.

[31] Shibuya N, Goldstein IJ, Broekaert WF, Nsimba-Lubaki M, Peeters B, Peumans WJ (1987) The elderberry (Sambucus nigra) bark lectin recognizes the Neu5Ac(alpha26)Gal/GalNAc sequence. J Biol Chem 262:1596-1601.

[32] Kirkeby S, Martel CJM, Aåsted B (2009) Infection with H1N1 influenza virus affects the expression of sialic acids of metaplastic mucous cells in the ferret airways. Virus Res 225-232.

[33] Kirkeby S (2016) Binding of fluorescently labeled cholera toxin subunit B to glycolipids in the human submandibular gland and inhibition of binding by periodate oxidation and by galactose. Biotech \& Histochem 91: 1-8.

[34] Klebanoff SJ, Kettle AJ, Rosen H, Winter bourn CC, Nauseef WM (2013) Myeloperoxidase: a fron-line defender against phagocytosed microorganisms. J Leukoc Biol 93: $185-198$. 
[35] Høiby N, Ciofu O, Bjarnsholt, T (2010) Pseudomonas aeruginosa biofilms in cystic fibrosis. Invited review. Future Microbiol 5:1663-1674.

[36] Børsholt Rudkjøbing V, Aanaes K, Yding T, Wolff, T, von Buchwald, C, Krogh Johansen H, Rolighed Thomsen T (2014) An exploratory study of microbial diversity in sinus infections of cystic fibrosis patients by molecular methods. J Cyst Fibros 13: 645-652.

[37] Degroote S, Ducourouble MP, Roussel P, Lamblin G (1999) Sequential biosynthesis of sulfated and/or sialylated Lewis $\mathrm{X}$ determinants by transferases of the human bronchial mucosa. Glycobiology 9:199-1211.

[38] Choi S, Park YS, Koga T, Treloar A, Kim, KC (2011) TNF- $\alpha$ is a key regulator of MUC1, an anti-inflammatory molecule, during airway pseudomonas aeruginosa infection. Am. J. Respir. Cell Mol Biol 44: 255-260.

[39] Umehara T, Kato K, Park YS, Lillehoj EP, Kawauchi, Kim, KC (2012) Prevention of lung injury by Muc1 mucin in a mouse model of repetitive Pseudomonas aeruginosa infection. Inflamm Res 61: 1013-1020.

40] Lillehoj EP, Hyun SW, Kim BT, Zhang XG, Lee DI, Rowland S, Kim KC (2001) Muc1 mucins on the cell surface are adhesion sites for Pseudomonas aeruginosa. Am J Physiol Lung Mol Physiol 280: L181-L187.

[41] Lillehoj EP, Kim BT, Kim KC (2002) Identification of Pseudomonas aeruginosa flagellin as adhesin for Muc1 mucin. Am J Physiol Lung Mol Physiol 282: L751-756. 
[42] Thornton DJ, Carlsted I, Howard M, Devine PL, Price MR, Sheehan JK (1996) Respiratory mucins: identification of core proteins and glycoforms. Biochem J 316: 967-975.

[43] Li JD, Dohrman AF, Gallup M, Miyata S, Gum JR, Kim Y, Nadel Prince A, Basbaum B (1997) Transcriptional activation of mucin by Pseudomonas aeruginosa liposaccharide in the pathogenesis of cystic fibrosis lung disease. Proc Natl Acad Sci USA 94: 967-972.

[44] Chorley, B.,N, Crews, A.,L, li, Y, Adler, K.B., Minnicozzi, M., Martin, L.D (2006) Differential Muc2 and Muc5ac secretion by stimulated guinea pig tracheal epithelial cells in vitro. Respiratory Res. 7:35

[45] Duncan TJ, Watson NFS, Al-Attar A, Scholefield JH, Durrant LG (2007) The role of MUC1 and Muc3 in the biology and prognosis of colorectal cancer. World J Surg Oncol 5:31.

[46] Chorley BN, Crews AL, Li Y, Adler KB, Minnicozzi M, Martin LD (2006) Differential Muc2 and Muc5ac secretion stimulated guinea pig tracheal epithelial cells in vitro. Resp Res $7: 35$.

[47] Kesimer M, Ehre C, Burns KA, Davis CW, Sheehan JK, Pickles RJ (2013) Molecular organization of mucins and glycocalyx underlying mucus transport over mucosal surfaces of the airways. Mucosal Immunol 6: 379-392.

[48] Sepper R, Prikk K, Sergejeva S, Pugatsjova N,Bragina O, Marran S, Fehniger TE (2012) Mucin5B expression by lung alveolar macrophages is increased in longterm smokers. J Leukoc Biol 92: 319-324.

\{49] Prior K (2016) May Journal club summaries. Thorax 69: 501 
[50] Davril M, Degroote S, Humbert P, Galabert C, Dumur V, Lafitte JJ, Lamblin G, Roussel P (1999) The sialylation of bronchial mucins secreted by patients suffering from cystic fibrosis or from chronic bronchitis is related to the severity of airway infection. Glycobiology 9: 311-321.

[51] Ramphal R, Pyle M (1983) Evidence for mucins and sialic acid as receptors for Pseudomonas arruginosa in the lower respiratory tract. Infect Immun 41: 339-344.

[52] Schulz BL, Sloane AJ, Robinson LJ, Prasad SS, Lindler RA, Robinson M, Bye PT, Nielson DW, Harry JL, Packer NH, Karlsson NG (2007) Glycosylation of sputum mucins is altered in cystic fibrosis patients. Glycobiology 17: 698-712.

[53] de Bentzmann S, Roger P, Dupuit F, Baolet-Laudinat O, Fuchey C, Plotkowski MC, Puchelle E (1996) Asialo GM1 is a receptor for Pseudomonas aeruginosa adherence to regenerating respiratory epithelial cells. Infect Immun 64: 1582-1588.

[54] Johansen, H.K, Aanaes, K, Pressler ,T., Nielsen, K.G., Fisker, J., Skov, M., Hoiby., N., von Buchwald, C (2012) Colonisation and infection of the paranasal sinuses in cystic fibrosis patients is accompanied by a reduced PMN response. J. Cyst. Fibros. 12: 525-531.

[45] Ciofu O, Hansen, CR, Høiby N (2013) Respiratory bacterial infections in cystic fibrosis. Curr Opin Pulm Med 19: 251-258. (7) 8 


\section{Illustrations.}

Fig.1. Sections of healthy control mink (Figs. A, C and E) and mink that were inoculated with Pseudomonas aeruginosa (Figs B, D and F) stained with HE-PAS-Alcian blue.

Control animals: The nasal cavity is covered with continuous respiratory epithelium. Two turbinates are shown in Figs.A and C. The green arrow in Fig. A marks the osseous part of a turbinate. In Fig.C the goblet cells are marked by a green arrow. The goblet cells are present in the columnar epithelial cells and stained by Alcian Blue. The cytoplasm in the columnar cells and the loose connective tissue underneath the surface epithelium (the submucosa, marked $S$ ) is stained pink by eosin. The olfactory mucosa is composed of a pseudostratified epithelium that contains different cell types (Fig.E). The olfactory cilia are non-motile and are marked by an arrow. They are strongly stained by Alcian Blue. Beneath the epithelium (O) there is a loose vascular connective tissue with afferent nerves and many Alcian Blue positive exocrine glands (Bowmans glands; G).

Infected animals: Following the intra-nasal infection the connective tissue in the turbinates became swollen with edema and cellular infiltration and the surface epithelium was disintegrated (Fig.B). The green arrow in Fig.B marks the osseous part of a turbinate.

While the air channels contained no or few cells in the healthy mink they were filled with cellular debris (DE) in the infected animals. Many of the debris cells are stained by Alcian Blue (Fig.D).

In the olfactory region the morphology of the surface epithelium and the supporting connective tissue and the glands seem to be unaffected by bacterial inoculation (Fig. F).

Fig. 2. Immunohistochemical staining for myeloperoxidase in a turbinate from a normal (Fig.A) and from a diseased (Fig.B) animal. The contours of the turbinates are outlined with white line The submucosa in Fig.B contains many positive cells. Figs.C and D show the staining in the nasal 
1 cavities after incubation with the anti-pseudomonas aeruginosa antibody. The cellular debris (DE) in the air channels from the infected mink reacts strongly. The contours of the turbinates are

3 outlined with white lines.

4 Fig. 3. Figs.A-D illustrate the changes that takes place in mucin expression in the nasal turbinates after infection with Pseudomonas aeruginosa. The sections were stained with antibodies against MUC1 (Figs.A and B) and MUC2 (Figs.C and D). Figs. A and C show tissue from a healthy animal and Figs.B and D show tissue from an infected animal. The respiratory surface epithelium (EP) from the healthy animal was nearly non-reacting after incubation with anti-MUC1 while the epithelium from the infected mink was strongly stained. The antibody directed against MUC2 reacted with the glycocalyx (marked by an arrow) from both the control (Fig.C) and the inoculated (Fig.D) animal while only the underlying respiratory epithelium from the sick animal showed antMUC2 staining. Figs.E and F illustrate reaction for MUC5AC. Only few goblet cells are stained positive in the respiratory epithelium from the control mink (Fig.E) while there are numerous MUC5AC positive goblet cells in the epithelium from the inoculated animal (Fig.F).

Fig.4. Reaction pattern in the turbinates for MUC5B is shown in figs. A and B. A small-granular reaction is seen in the surface epithelium from both the infected and the healthy mink. The subepithelial tissue contains from the inoculated animals contains large MUC5B positive cells marked by arrowhead. Reaction pattern in the turbinates for asialo GM1 is depicted in Figs.C and D. There is virtually no reaction in the turbinates from the healthy mink (Fig.C) while almost all the epithelial cells react in the cells from the infected animal (Fig. D). Thickness of the epithelium is 21 indicated by arrows. Figs.E and F show MAA reaction in the turbinates. The goblet cells (marked by green arrows) in the respiratory epithelium from the healthy mink were almost blank after incubation with the lectin (Fig E) while they were strongly stained in the infected animals (Fig.F). 


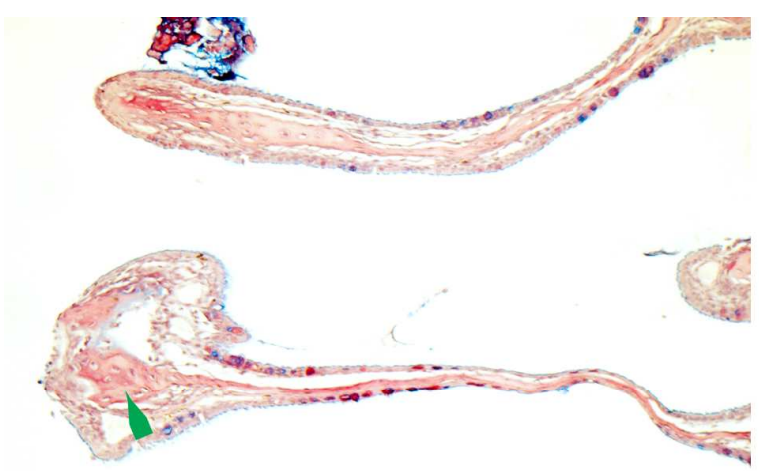

A

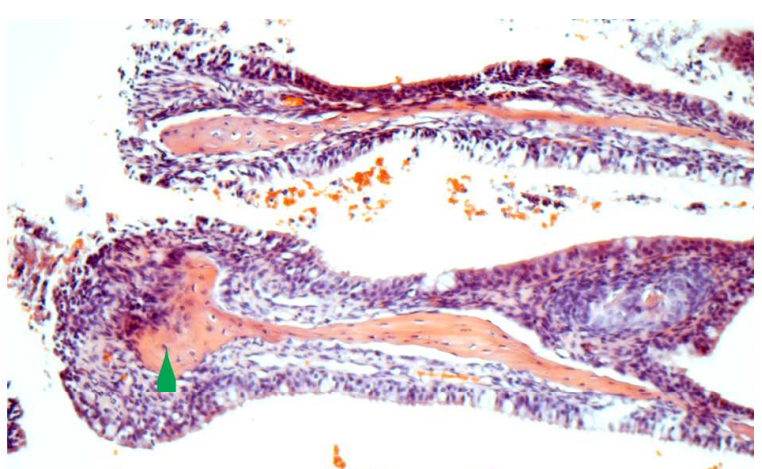

B
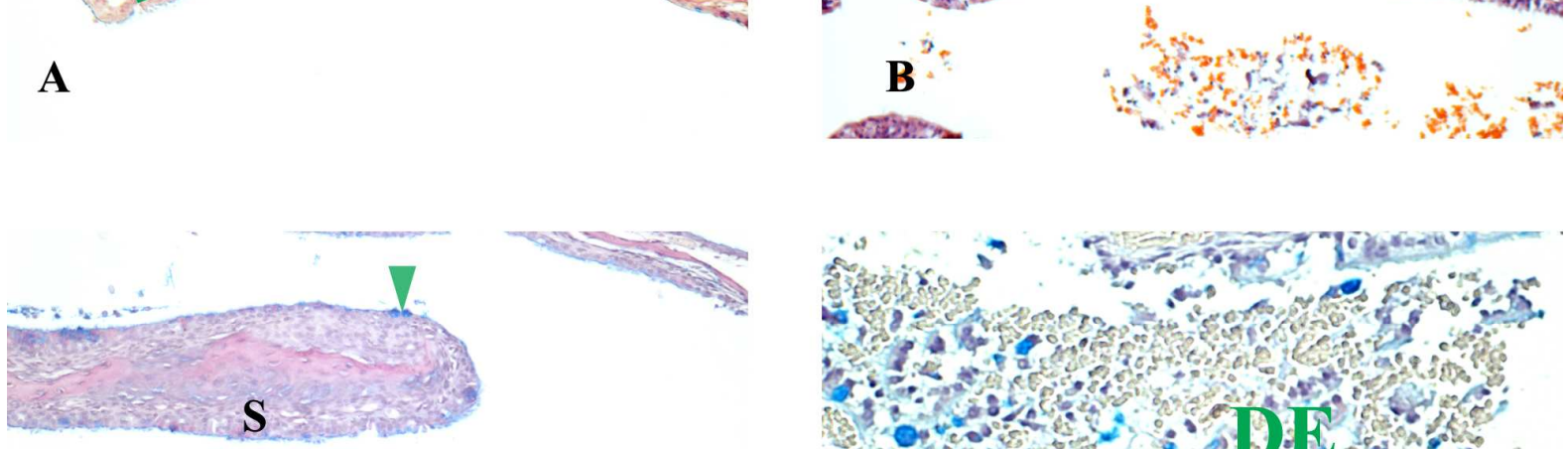

-

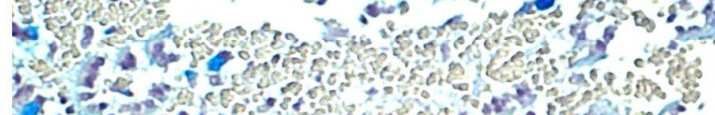

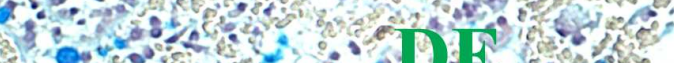

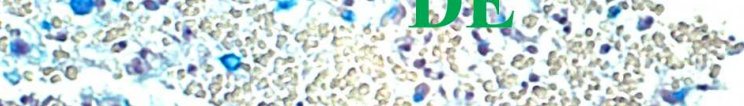

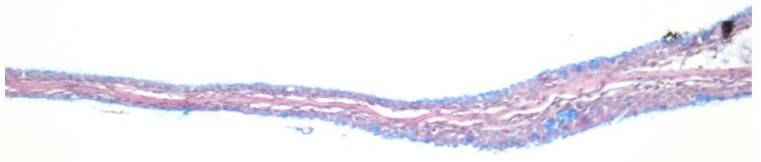

C
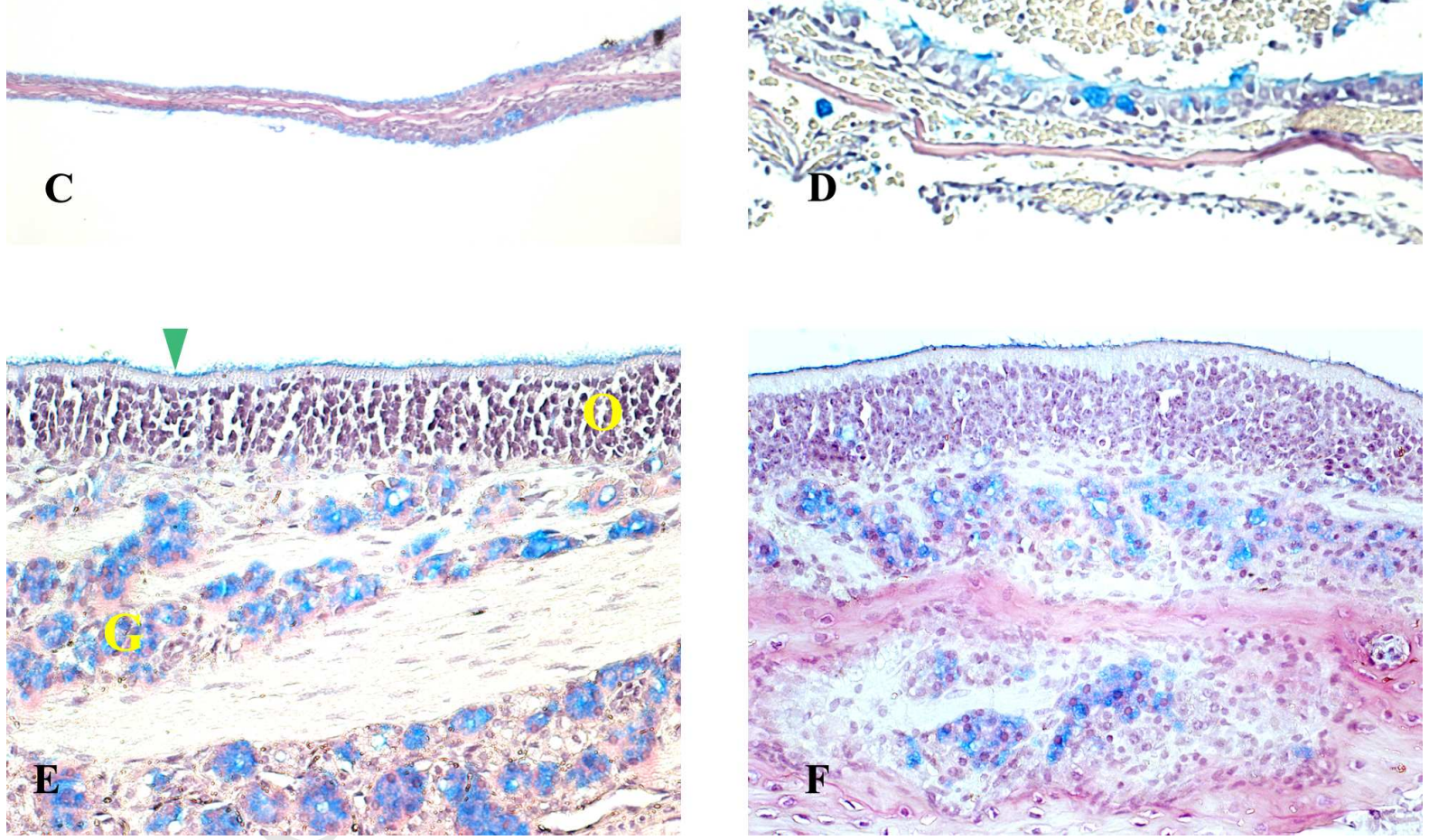


\section{ACCEPTED MANUSCRIPT}
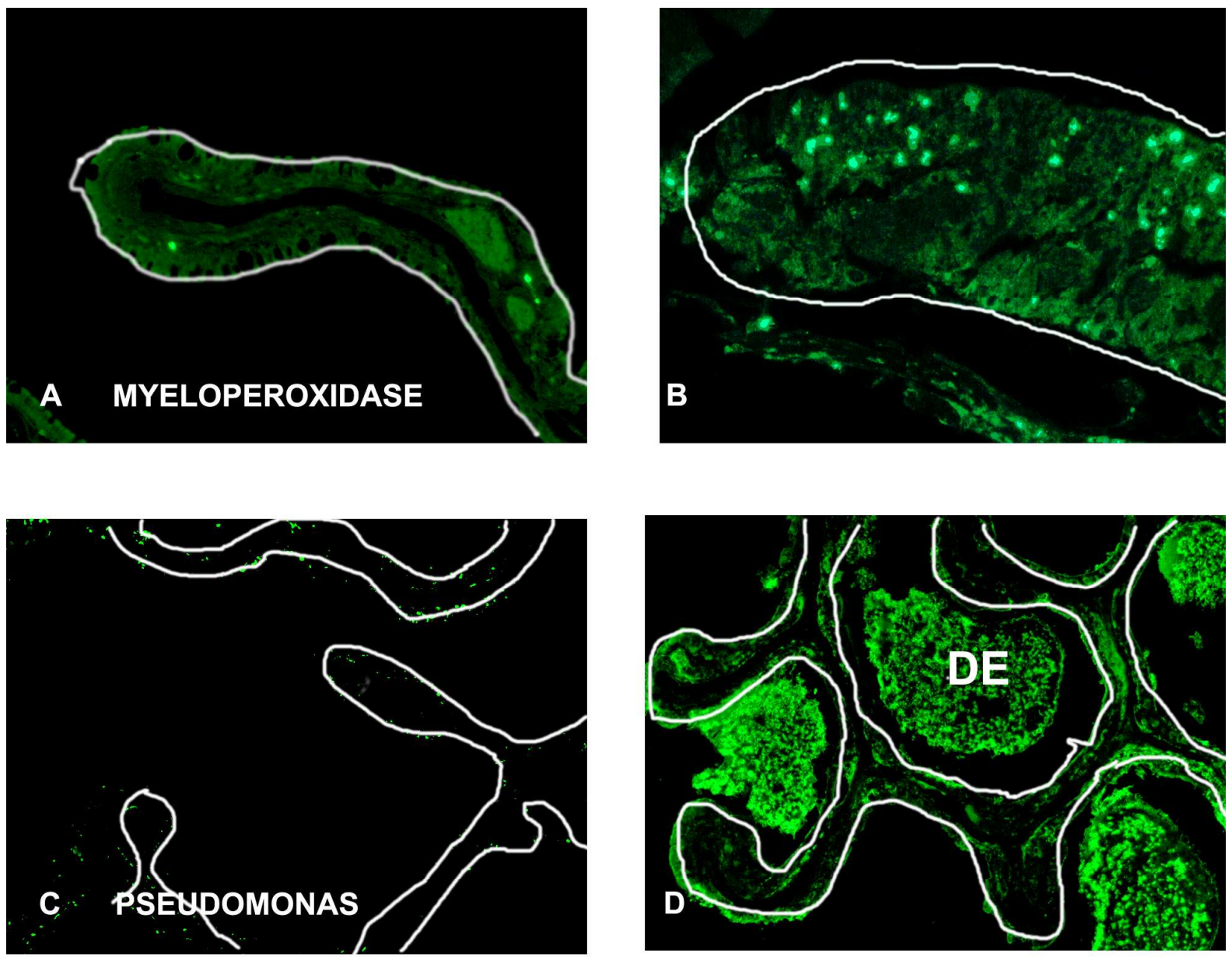


\section{ACCEPTED MANUSCRIPT}
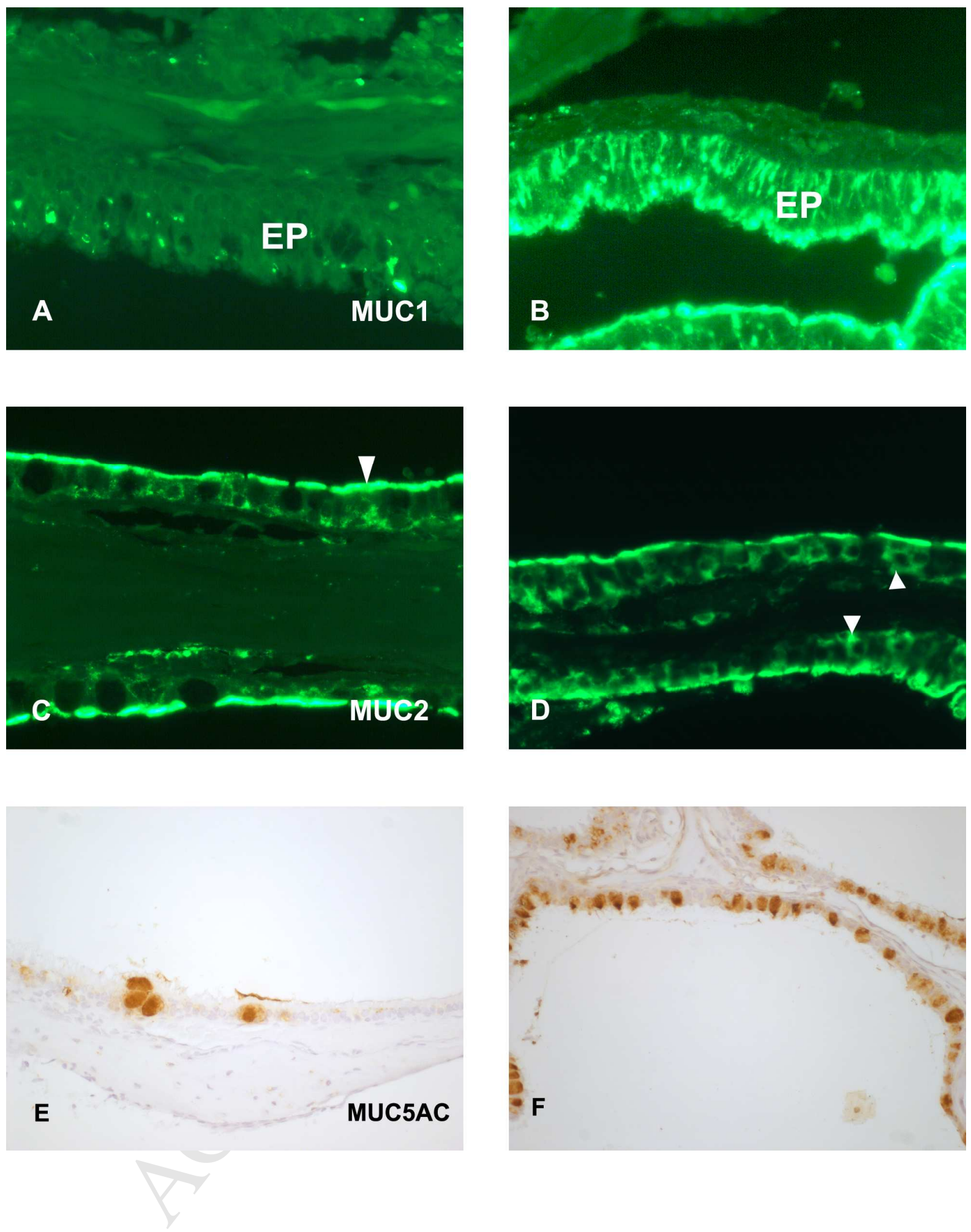

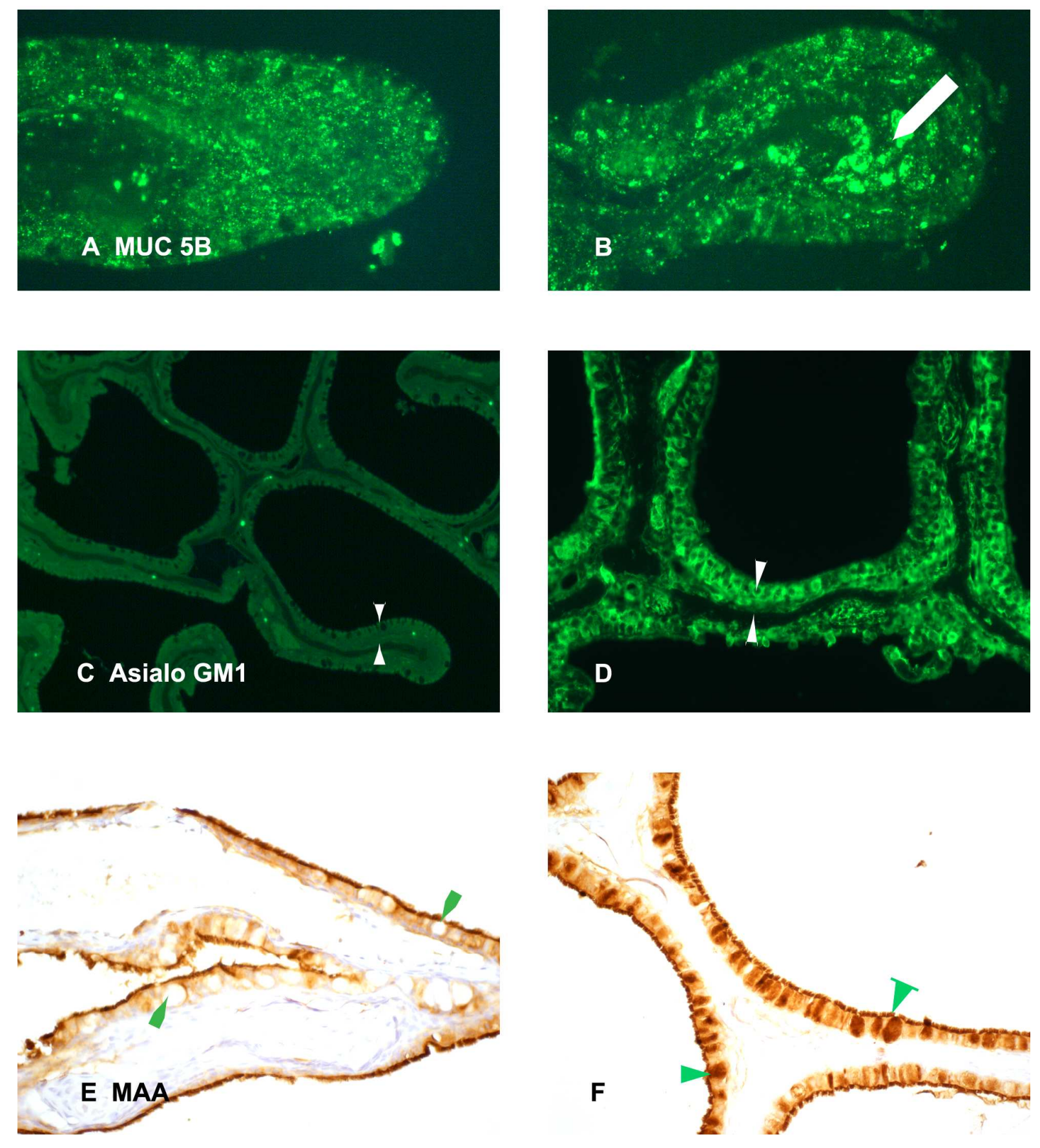